amputations in a large provincial hospital, spread over a period of two years, with six deaths-5.7 per cent.--none of which were due to hospital causes, is a result which a few years ago, certainly at the time Sir James Y. Simpson wrote his article on "Hospitalism," few, if any, hospitals could show, and speaks eloquently for the improved method of treating wounds, which Sir J. Lister has done so much to perfect.

Newcastle-on-Tyne.

\section{ON A CASE OF}

\section{ILIO-FEMORAL ANEURYSM, TREATED BY INSTRUMENTAL COMPRESSION ; CURE.}

BY W. BERRY, M.R.C.S., L.R.C.P. \& S. ED., HONORARY SURGEON TO THE ROYAL ALBERT EDWARD INFIRMARY, WIGAN.

THE notes of the following case of ilio-femoral aneurysm are interesting, especially as they prove the dictum of Mr. Bryant in his work on Surgery, page 463, second edition, where, in writing of ligature of the external iliac artery, he says: "This operation may be required for aneurysm of the common femoral for wound or for any other cause in which it is necessary to arrest the flow of blood through the lower extremity. It should not, however, be performed for any disease unless pressure of the artery, digital or instrumental, has proved ineffectual or is inapplicable; for Mapother, ${ }^{1}$ Eck, ${ }^{2}$ and Hilton ${ }^{3}$ have all recorded instances of cure of inguinal aneurysm by these means." This case was sent to me by my friend, Dr. Hannah of Ashton-in-Makerfield, and my first intention was to ligature the external iliac, this operation to my mind affording the only chance of cure. At a consultation with my colleagues of the infirmary staff it was thought advisable to try pressure in the first instance, and if failure followed, then to ligature the vessel above the aneurysm. The application of compression was not easy to accomplish, and much credit is due to the indefatigable perseverance and ingenuity of our senior house-surgeon, Dr. Jackson, and also to the courage exhibited by the patient himself, which led to a successful result as a reward for their efforts. I am indebted to Dr. Jackson for the following notes:-

George S-, aged forty years, a collier, was admitted into the Royal Albert Edward Infirmary on Aug. 21st, 1884. He then stated that whilst following his employment seven weeks previously he had been injured in the right thigh by a runaway coal-tub. Immediately after the injury he felt a shooting pain in the region of the right groin, which lasted about fifteen minutes. There was no external wound or abrasion of the skin, but poultices were applied on account of the pain. Patient continued to work, and about two days afterwards noticed a small lump in the right groin, which had continued to enlarge. He continued to work until a week after the accident, when he was idle for three weeks, in consequence of a lock-out at the colliery; after this he worked one week, and then "strained" himself again, and was laid up. The patient has been married sixteen years, and has three healthy children; he lost one, aged fourteen months, from consumption of the bowels. There is no history of syphilis, but there is a circular scar about the middle of the dorsum of the penis, which he states was caused by a wound he received in the mine. He had gonorrhœea twenty years ago. On examination, a pulsating tumour, the size of a large walnut, was found immediately below the right Poupart's ligament, at a point corresponding with the position of the femoral artery. The patient was placed on milk diet, and ten grains of iodide of potassium, three times a day, were ordered. On Sept. 2nd he went home, against the wish of the housesurgeon, without any improvement having taken place. On Oct. 1st he was readmitted. The tumour could now be felt pulsating above Poupart's ligament and as far down as a point two inches below it, and was one inch in width. The patient was again put on milk diet and fifteen-grain doses of iodide of potassium three times a day, and after a consultation with the staff it was decided to apply pressure to the external iliac artery. On the 9 th the patient was placed in a small ward alone, and at 2 P.M. had three-quarters of a grain of morphia hypodermically and the right leg enveloped in a fold of cotton

1 Dublin Medical Press, 1865.

2 St. Bartholomery's Hospital Reports, 1866

3 Medical and Chirurgical Transactions, 1869. wadding. Pressure was then applied to the external iliac by means of a Lister's tourniquet until the pulsation in the tumour ceased. In about half an hour the patient became very restless and complained of pain, and all circulation in the limb appeared to have ceased. He was then allowed to smoke, and, having been deprived of this (a favourite enjoyment of his) for over a week, submitted cheerfully to the pain for another hour. At 3.30 P.M. the pain was so severe that chloroform had to be administered, and this was continued until 6.15 P.M., making in all four hours and a quarter of continuous pressure, when the tourniquet was removed. On the 10th the pulsation in the tumour was slightly (?) diminished, the patient feeling comfortable. On the following day the patient was in much the same condition. The bowels were relieved by a dose of castor oil. On the 12th the pulsation in the tumour was apparently as strong as ever; the leg was flexed on the thigh and the thigh on the abdomen with a roller bandage in the groin, for one hour and a half both morning and evening. Next day the leg was again flexed, as before, for two bours and a half. No result followed this procedure. On the 14th the pulsation was as strong as at the commencement of treatment, pressure was again applied by Lister's tourniquet, with the aid of tobacco and chloroform, for three hours and a half. Pulsation in the tumour had entirely ceased when the pressure was removed. The following day the pulsation had ceased; the limb was cold but the patient was comfortable. On the 16 th the circulation in the limb returned. On the day following there was no pulsation in the tumour, which was quite solid. The circulation in the limb was quite re-established through collateral channels. The patient went on well, and was discharged cured on Nov. 3rd, 1884. At this time a firm tumour could be felt an inch and a half in length and an inch in width at the seat of the aneurysm, but no pulsation, and the circulation in the limb perfectly good.

Jan. 27th, 1885.-Patient seen and examined to-day. Tumour now feels like a thickened cord about three-quarters of an inch thick; no pulsation in it. Circulation in limb keeps good, but he is advised to nurse his leg yet awhile.

Remarks.-This case, though unfavourable for direct pressure owing to the circumstance of its position, yet by the result amply repays one for the trial made. I must here tender my thanks to Dr. Jackson for his patience and perseverance in the treatment of this case, for had he not sat by the patient and kept the tourniquet fairly in position over the artery, I am sure we should not have been able to record this successful issue.

Wigan.

ON

\section{SYNCOPE, AND A METHOD OF AVERTING IT.}

\section{BY WILLIAM J. NOTLEY, M.D., B.A. LOND,}

IN whatever way syncope may be produced, whether by an impression made primarily on the higher cerebral centres, or by influences carried along the peripheral nerves to these centres, and thence in both cases reflected to the heart and other organs of the body, there can be no doubt that the unconsciousness, either partial or complete, which forms the principal symptom of the condition is due to a deficient supply of blood to the brain. Cases of syncope may be divided into two classes: first, those which are due to some mechanical obstruction to the circulation arising in the heart itself, or in the great vessels springing from it, and secondly, those which are the result of various impressions made either on the peripheral nerves or on the emotional centres in the cerebrum. To the former class belong those cases of valvular and aortic disease which terminate in fatal syncope, as well as those in which, from the weakness of the circulation at the end of exhausting maladies, ante-mortem clots are formed, which, by interfering with the exit of the blood, terminate the life of the patient.

In the other class of cases the cause is often external to the organism. A blow on the abdomen, by its effect on the mesenteric nerves, gives rise to an impression which, travelling along the spinal cord, reaches the medulla, and is thence transmitted along the vagi to the heart, resulting in a retardation or a complete stoppage of that organ. The same effect, it is well known, may arise from an impression made on the terminations of any of the afferent nerves 
provided it be sufficiently strong to produce, not merely a sensation, but also a reflection. In other cases belonging to the same class the impression is made primarily on the higher centres of the brain, and is in the nature of an emotion of joy or fear, or some other strong passion. From these centres, if the impression is strong enough, or if the nervous system is in that state of mobility allied to weakness, in which the liberating forces are in excess of the inhibiting ones, the impression is conducted to the medulla, and from it to the heart, along the same channels as those before named.

Now, in all cases where the syncope is not complete, and where the heart continues to act, though feebly, measures are usually taken to restore the patient by adopting such means as are calculated to strengthen the action of the heart and facilitate the flow of blood to the brain. In many cases a person accustomed to faint from slight causes will be able to avert the syncope by adopting such means, and it is for this purpose that I wish to draw attention to the efficacy of heat applied to the head. In a person with a weak heart syncope may be produced by simply sitting with the feet in hot water, and, in like manner, it may be averted by the application of heat to the head. Anyone may convince himself of this by first producing faintness in himself artificially. This may easily be done by getting into a bath of about $110^{\circ} \mathrm{F}$. In a few minutes he will begin to feel faint. Let him then plunge the whole of his head except the nose and mouth beneath the surface of the water, and in less time than it has taken to bring on the faintness all the disagreeable sensations will cease, and he will now be able to continue in the bath, perhaps for half an hour longer, without any inconvenience. From this it would appear that the application of heat to the head is a measure of some value in averting a threatened attack of syncope.

Birmingham.

\section{A}

\section{H O S PITAL PRACTICE, BRITISH AND FOREIGN.}

Nulla antem est alia pro certo noscendi via, nisi quamplurimas at morborum et dissectionum historias, tum aliorum tum proprias collectas habere, et inter se comparare. - MoRGAGnI De Sed. et Caus. Morb. lib. iv. Procemium.

\section{ST. MARY'S HOSPITAL.}

FORMER DESTRUCTIVE ARTHRITIS OF THE KNEE-JOINT; DISLOCATION WITH EONY AND FIBROUS ANKYLOSIS; RESECTION; UNION BX FIRST INTENTION AND WITHOUT SUPPURATION.

(Under the care of Mr. A. T. NonToN.)

OssEous ankylosis of the knee-joint with backward displacement and rotation of the leg, rendering the patient quite unable to walk, as in the case described below, is usually the result of inflammatory changes following injury. It is now comparatively rare to meet with extreme degrees of such deformity, careful attention on the part of the medical attendant and improved methods of treatment preventing such result. The operation which Mr. Norton performed in this case, removal of a wedge-shaped piece, including parts of the femur and tibia with the patella, is the best when the deformity is the result of disease, as in his case; it permits of removal of any lurking mischief, as mell as correction of the deformity. The other operations which have been practised for the cure of this condition are, briefly, fracture of the femur after subcutaneous drilling of the bone, excising a wedge-shaped portion of the femur above the joint, osteotomy of the femur and of the tibia, and subcutaneous division of the line of union by means of a chisel or other instrument introduced from the outer side, followed by gradual extension of the limb.

For the following notes we are indebted to Mr. French.

The patient, E. Wten, was admitted into St. Mary's Hospital on Sept. 30th, 1884. The family history was good. The patient herself had always been healthy but had suffered from corneal ulcers, the scars of which could be seen in the left eye. The history was that four years ago, without any known cause, the left knee began to strell and became painful, especially when the patient attempted to walk. To ease the pain she kept the joint flexed and used a crutch to get about. There had been no suppuration.

On admission the left knee-joint was found to be uniformly enlarged with a good deal of pulpy synovial membrane and firmly or immovably ankylosed with the leg almost at a right angle with the thigh, and the lower bones dislocated backwards, outwards, and rotated outwards. The patella was also ankylosed to the femur. The knee was not tender and only painful when weight was put upon it. There was wasting of the muscles of the limb. The ankylosis was so firm, not only within the joint but without it, and the dislocation of the tibia from the femur so great, that it was clearly evident that the deformity could not be overcome. The limb in that condition was quite useless to the child. She was unable to bring the foot to the ground and could only walk by means of crutches. It was, therefore, decided to resect the joint.

On October 15th, after consultation, the patient was taken into the theatre and put under ether, and Mr. Norton proceeded to excise the joint. The circulation was arrested by the Esmarch cord. The usual horseshoe incision was made, and the flap dissected up from the patella. The capsule and ligamentum patellæ were then cut through, and the tibia forcibly flexed on the femur, but it was impossible to break down the ankylosis, which was bony, even with the raspatory and lever. Almost the whole of the lower epiphysis of the femur with the patella attached, and a slice of the upper end of the tibia, were then sawn off. The ends of the bone were adjusted, and the edges of the wound were brought together with wire sutures. A small drainage-tube was inserted at each side of the joint, not through the wound, which was entirely closed, but through small openings made for the purpose. The operation was performed under the spray and the wound dressed with Listerian dressings and salicylic wool. After the operation the limb was put up on a back splint made to fit the child with outside splint attached, and interrupted in the region of the wound in order to apply the antiseptic drissings. Ice-bags were suspended on the leg both above and below the dressings. After recovering from the anæsthetic, the patient was very restless, so one-eighth of a grain of morphia was administered subcutaneously, and minim doses of sedative solution of opium ordered to be given every hour if necessary; but during the night three doses of one minim each were given.

On the following day the knee was dressed; there was a small amount of serous discharge. Tubes syringed out with iodine lotion (half a drachm to the ounce). The patient complained of slight pain in the knee. Morning temperature $99 \cdot 5^{\circ}$, evening $101 \cdot 3^{\circ}$.

The knee was dressed again on the following day, after which it was left for three days as no discharge came through the dressings, the highest temperature being on the third evening, $101 \cdot 3^{\circ}$.

On the 26th the stitches were taken out, the whole wound having united by first intention, except where the tubes were. The tubes were shortened at each time of dressing, and finally left out on Nov. 6 th, when the bones were found to be firmly united, three weeks after the operation.

The interrupted splint was left off on the 13th, and an iron back splint was applied; the Listerian dressings were also discontinued and the knee dressed with salicylic wool.

On the 18th a small superficial abscess formed in the upper flap, which was opened, and half a drachm of pus escaped; the cavity was circumscribed and did not extend to the bone.

On the 27th the note is as follows:- "The patient can stand without pain and walk without assistance and without crutches. On measurement there is found to be two inches and a half shortening of the affected limb, but this is not very visible when the patient stands up, even with ordinary boots on."

She was discharged with the wound perfectly healed on Nov. 27 th, six weeks after the operation.

\section{LIVERPOOL ROYAL INFIRMARY}

CASE OF COMPOUND DISLOCATION OF THF ELBOW-JOINT, WITH DIVISION OF THE MAIN ARTERY AND VEIN,

HEALED WITH RESTORATION OF ALL MOVEMEYTS ; REMARKS.

(Under the care of Mr. Rushton Parker.)

A Woman, aged twenty-eight, fell downstairs on April 13th, 1883, and was admitted into the Liverpool Royal Infirmary shortly afterwards. The house-surgeon on duty, Mr. 